\title{
O CENÁRIO DA HISTÓRIA DA ÁFRICA NO ENSINO SUPERIOR: \\ UNIVERSIDADE FEDERAL FRONTEIRA SUL (UFFS), UNIVERSIDADE DO \\ ESTADO DE SANTA CATARINA (UDESC) E UNIVERSIDADE DO EXTREMO SUL \\ DE SANTA CATARINA (UNESC)
}

\author{
Paulino de Jesus Francisco Cardoso ${ }^{1}$ \\ Aline Rafaela Lelis ${ }^{2}$ \\ Carol Lima de Carvalho ${ }^{3}$ \\ Ticiane Caldas de Abreu ${ }^{4}$ \\ Ana Júlia Pacheco ${ }^{5}$
}

\begin{abstract}
Resumo: O presente trabalho busca compreender de que forma os conteúdos relativos à História da África vem sendo ensinado nos cursos de graduação em História das Instituições de Ensino Superior (pública, comunitária e particular) do estado de Santa Catarina, tendo em vista a obrigatoriedade estudo da temática nas redes de ensino prevista na Lei Federal 10.639/03. A finalidade é analisar as possibilidades e perspectivas de abordagem da temática através dos planos de ensino do ano de 2014 das disciplinas de História da África das respectivas instituições: Universidade Federal Fronteira Sul (UFFS), Universidade do Estado de Santa Catarina (UDESC) e Universidade do Extremo Sul Catarinense (UNESC).

Palavras-chave: História da África. Ensino Superior. Santa Catarina. Lei Federal $10.639 / 03$.
\end{abstract}

\section{THE SCENERY OF AFRICAN HISTORY IN HIGHER EDUCATION: \\ UNIVERSIDADE FEDERAL FRONTEIRA SUL (UFFS), UNIVERSIDADE DO \\ ESTADO DE SANTA CATARINA (UDESC) E UNIVERSIDADE DO EXTREMO SUL \\ DE SANTA CATARINA (UNESC)}

Abstract: The present study seeks to understand how the contents related to African history has been taught to future teachers of History courses in higher education institutions

1 Doutor em História. Professor adjunto do Departamento de História e do Programa de Pós-graduação em História da Universidade do Estado de Santa Catarina (UDESC). Presidente da Associação Brasileira de Pesquisadores/as Negros/as (ABPN). Coordenador do Núcleo de Estudos Afro-brasileiros (NEAB/UDESC). Email: paulino.cardoso@gmail.com.

2 Mestra pelo Programa de Pós-graduação em História da Universidade do Estado de Santa Catarina (UDESC). Pesquisadora Associada ao Núcleo de Estudos Afro-brasileiros (NEAB/UDESC). E-mail: a.rafaelalelis@gmail.com. Graduanda em História pela Universidade do Estado de Santa Catarina (UDESC). Bolsista de Iniciação Científica do Núcleo de Estudos Afro-brasileiros (NEAB/UDESC). E-mail: carolimac18@gmail.com.

4 Graduanda em História pela Universidade do Estado de Santa Catarina (UDESC). Bolsista de Iniciação Científica do Núcleo de Estudos Afro-brasileiros (NEAB/UDESC). E-mail: ticianecda@gmail.com.

5 Mestranda do Programa de Pós-graduação em História da Universidade Federal do Rio Grande do Sul (UFRGS). Pesquisadora Associada ao Núcleo de Estudos Afro-brasileiros (NEAB/UDESC). E-mail: anajulia. hp\#@gmail.com. 
(public, community and private) in the state of Santa Catarina, regarding the Federal Law $10,639 / 03$ which made mandatory the study of the subject in school systems. The purpose is to analyze the possibilities and thematic approach prospects through the teaching plans of 2014 of African History disciplines in the following Public and Community Universities: Federal University of Southern Border (UFFS), Santa Catarina State University (UDESC), and the University of Extremo Sul Catarinense (UNESC).

Keywords: African History. Higher Education. Santa Catarina State. Federal Law $10.639 / 03$.

\section{Introdução: na trajetória do tema}

Por meio do projeto de pesquisa intitulado O Ensino de História de Áfricas em Santa Catarina: questões e perspectivas, vinculado ao Núcleo de Estudos Afro-Brasileiros da Universidade do Estado de Santa Catarina (NEAB/UDESC) e desenvolvido pelo grupo de pesquisa Multiculturalismo: Estudos Indígenas, Africanos e da Diáspora, buscamos desde o segundo semestre do ano de 2012 mapear a formação dos/as professores/as que lecionam a disciplina de História e Cultura da África, e os componentes curriculares aplicados nos cursos de graduação de licenciatura e bacharelado em História nas instituições de Ensino Superior (públicas, comunitárias e particulares) do estado de Santa Catarina. De maneira geral, esta pesquisa busca refletir sobre os modos como a História da África está sendo ensinada aos futuros docentes.

A partir da inconstante luta do Movimento Negro ao longo das últimas décadas foi possível estabelecer as políticas de reparação histórica no Brasil. Na perspectiva educacional, tencionando o contexto de invisibilidade acerca das experiências das populações de origem africana, foi sancionada em 2003 pelo então presidente da república Luís Inácio Lula da Silva, a Lei Federal 10.639 tornando obrigatório para todas as instituições de ensino básico, públicas e privados, o ensino de História e Cultura da Africana e Afro-Brasileira. Segundo Jeruse Romão (2014), com a sanção da Lei foi possível impulsionar para que as temáticas referentes às culturas africanas e afro-brasileiras atingissem um novo patamar no contexto da educação brasileira. Após sua aprovação, aquilo que estava previsto como políticas passaram a fazer parte da Lei de Diretrizes e Bases da Educação Nacional possibilitando a diminuição da invisibilidade das políticas para educação das relações étnico-raciais no Brasil.

Embora passado mais de 10 anos de sua promulgação, diferentes indicadores têm refletido sobre as dificuldades para que haja efetivamente sua implementação. Tal como apontado por Amilcar Araújo Pereira (2011) é consenso entre todos que trabalham nesse campo de es- 
tudo que há muito que ser feito em termos de pesquisa e ensino para que a determinação legal seja cumprida e possa alterar o aspecto eurocêntrico ainda tão presente no ensino de História nas escolas brasileiras.

Wilson Mattos e Patrícia Pena (2013) sublinham considerações críticas em relação ao início dos estudos acerca da História da África no Brasil, buscando enfatizar o processo de construção da legitimidade deste tema no âmbito acadêmico, dentro do contexto legal e normativo a partir da Lei 10.639/03. Segundo eles, quando o objetivo é atender as diversas demandas educacionais e políticas provocadas pelas determinações da referida Lei, as universidades brasileiras devem passar a oferecer disciplinas e outros componentes curriculares nos seus cursos de graduação.

Vale ressaltar que as Diretrizes Curriculares Nacionais para a Educação das Relações Étnico-Raciais e para o Ensino de História e Cultura Afro-Brasileira formulada em 2004 também orientam formas de cumprimento desse dispositivo legal nos cursos superiores de formação de professores/as e de profissionais da educação, bem como aqueles que não estão relacionados á formação docente ou às áreas das ciências humanas. Para Anderson Oliva (2009) as DCN's avançam indo além das referências aos conteúdos a serem apresentados aos alunos, sinalizando para a necessidade de inclusão, nos cursos de formação de professores e profissionais da educação e de materiais e de textos didáticos na perspectiva de estimular o ensino e aprendizagem da temática africana. Assim segundo ele, a mesma indicação é feita a outros cursos superiores, não relacionados às áreas das Ciências Humanas, “demonstrando a preocupação em ampliar, ao máximo, a abordagem da questão pelos bancos escolares e universitários brasileiros" (OLIVA, 2009, p. 158).

Dessa forma, a pesquisa visa mapear, monitorar e garantir a implementação da Lei no curso de História das instituições catarinenses de ensino superior, investigando especialmente qual história da África está sendo ensinada nos espaços acadêmicos. Mônica Lima (2004, p. 84) enfatizou aquilo que esta investigação também busca: atentar-se ao docente sobre a efetivação daquilo que está nos documentos. Significando assim, buscar o que é determinado por elas a respeito do ensino da história e das culturas africanas e afro-brasileiras nas Instituições de Ensino Superior. Afinal segundo ela "Que história será esta, se a maioria dos professores em atividade não a conhece?". 
Neste sentido, a utilização dos planos de ensino para o desenvolvimento da pesquisa é pelo fato de que é o/a docente que estabelece os caminhos que a disciplina irá percorrer, e estes/as pensam e selecionam o que consideram pertinente para o estudo da temática, respeitando as especificidades dos documentos de cada instituição. Segundo a autora Mariana Heck (2013) " [...] pensamos ser importante reafirmar que, tendo como ponto de partida as legislações, as determinações e o contexto das instituições, é o/a professor/a quem determina quais conteúdos e a perspectiva utilizada em sala de aula." Assim, os planos de ensino nos possibilitam perceber por quais caminhos teórico-metodológicos os professores optaram a partir do que já estava posto para a disciplina em seus projetos políticos pedagógicos de curso.

O texto que se segue, analisa as possibilidades e perspectivas de abordagem da temática através dos planos de ensino do ano de 2014 da disciplina de História da África da Universidade Federal Fronteira Sul (UFFS), Universidade do Extremo Sul Catarinense (UNESC) e Universidade do Estado de Santa Catarina (UDESC).

\section{Escolhas, perspectivas e possibilidades: os planos de ensino das disciplinas de história da África}

Neste momento pretendemos apontar algumas questões referentes à análise realizada dos planos de ensino das universidades públicas Universidade do Estado de Santa Catarina (UDESC) $^{6}$ e Universidade Federal Fronteira Sul (UFFS) ${ }^{7}$, e comunitária Universidade do Extremo Sul de Santa Catarina (UNESC) ${ }^{8}$.

De maneira geral, esta análise foi realizada com o intuito de identificar de que forma a história da África está sendo ensinado/a aos/as futuros/as professores/as historiadores/as, assim, focamos primeiramente nas ementas de cada uma das disciplinas examinando se estão

6 Os planos de Ensino das disciplinas de História da África UDESC tem o seguinte formato: Identificação; Ementa; Horário das Aulas (opcional); Objetivos Gerais e Específicos; Conteúdo Programático; Metodologia; Cronograma das Aulas (opcional); Avaliação; e Bibliografia Básica e Complementar.

7 Os Planos de Ensino da disciplina de História da África da UFFS tem o seguinte formato: Identificação, Ementa da Disciplina, Justificativa da Disciplina, Metodologia, Objetivo Geral, Objetivos Específicos, Cronograma e Conteúdos Programáticos, Avaliação, Atendimento aos Estudantes e Referências Bibliográficas (Básicas e Complementares).

8 Os planos de Ensino das disciplinas de História da África UNESC tem o seguinte formato: Identificação; Objetivo do curso; Ementa; Objetivos principais da disciplina; Metodologia; Procedimentos de avaliação; Conteúdo Programático; e Bibliografia Básica e Complementar. 
articuladas com seus objetivos gerais e específicos, depois analisamos seus conteúdos programáticos buscando identificar se estão relacionados com a meta da disciplina história da África.

Para que esta pesquisa fosse concretizada, solicitamos às coordenadorias e departamentos dos cursos de História seus planos de ensino das disciplinas História da África ou de alguma disciplina que abordasse a temática ao longo do currículo. Por conseguinte, utilizando as fontes fornecidas pelas instituições foi possível analisar as características das disciplinas temáticas presentes nestas Instituições.

\section{Universidades públicas}

Universidade Federal Fronteira Sul (UFFS)

O curso de História da Universidade Federal Fronteira Sul (UFFS) visa formar professores para atuarem nas diferentes esferas do ensino de História, com habilidades e competências necessárias para pensar historicamente o mundo. Inclusa na matriz curricular do curso está à disciplina intitulada História da África, lecionada pela Professora Doutora Renilda Vicenzi. Esta docente possui graduação em História pela Faculdade de Filosofia Ciências e Letras (FFCLP /1996), mestrado em História pela Universidade de Passo Fundo (UPF/2003), doutorado em História pela Universidade do Vale do Rio dos Sinos (UNISINOS/2015) e é professora da UFFS - Campus Chapecó ${ }^{9}$. A análise feita visou contemplar o plano de ensino da disciplina ministrada pela Professora ao longo do segundo semestre do ano de 2014.

$\mathrm{Na}$ ementa da disciplina de História da África da UFFS consta que devem ser estudadas “Estruturas sócio-políticas e culturais da África do século XVI ao XXI. Processos de constituição dos sistemas coloniais e de descolonização. Abordagens historiográficas e suas perspectivas teóricas e de prática de ensino." (UFFS, 2014). No objetivo geral, a professora Vicenzi delimita que: "Estudar os processos históricos do continente africano, com ênfase nas relações internacionais estabelecidas a partir do século XVI, contemplando propostas de ensino e de pesquisa" (Idem).

9 Estas informações iniciais contidas neste parágrafo foram tecidas a partir da leitura do projeto político pedagógico de curso da UFFS e do currículo lattes da profa. Renilda Vicenzi. Todos esses documentos estão armazenados pela pesquisa. 
Podemos perceber que a professora visa estudar o processo histórico do continente africano numa perspectiva das relações internacionais, partindo do que Heck relata ser "dinamismo" que inclui as relações internas e externas ao continente, recortando cronologicamente os eventos históricos do continente africano a partir do XVI. A partir dos apontamentos de Leila Leite Hernandez, a autora Ana Júlia Pacheco (2014, p. 43) em seu trabalho, destaca questões a respeito das implicações da abordagem de África somente a partir do século XVI:

Leila Leite Hernandez (2005), historiadora brasileira, nos explica que o racionalismo como método, cuja gênese remonta o século XVI, consolida-se entre a segunda metade do século XVIII e a primeira da metade do século XIX, passando a dominar o pensamento ocidental, este, colaborou para a construção de um conhecimento que apresenta a idéia de uma história da civilização ocidental, que por conseguinte, trata de maneira equivocada, todo o referencial no que diz respeito ao continente Africano e seus agente. "Significa dizer, que o saber ocidental constrói uma nova consciência planetária constituída por visões de mundo, auto-imagens e estereótipos que compõe um “olhar imperial” sobre o universo" (HERNANDEZ, 2005, p. 17-18).

Ademais, é possível pensar que os objetivos gerais da disciplina, num determinado momento, não focam somente nas histórias do continente africano, por ele mesmo. Entretanto, segundo a autora Selma Pantoja (2004 p. 22) é preciso enunciar as origens da humanidade, discutir a questão da "anterioridade africana" e as relações ativas dos africanos com os oceanos e as outras partes do mundo, que dessa forma é possível chagar a uma abordagem da África por ela mesma. E então, seguindo a concepção de Pantoja, a Profa. Vicenzi traz a perspectiva de dinamismo e atende a estes princípios.

Em relação aos objetivos específicos, dentre os sete pontos apresentados, focamos em cinco que possibilitam uma articulação com a ementa proposta pelo curso:

\footnotetext{
— Compreender a construção do conhecimento acerca da história da África.

- Estudar os processos de organização das sociedades africanas, especificamente aquelas pertencentes a chamada África Sul Saariana, entre os séculos XVI e XIX. - Compreender as formas de escravidão que existiram na África visando problematizar as suas características.

- Conhecer e analisar as características do tráfico negreiro e da diáspora.

- Identificar os processos de independência ocorridos em algumas sociedades africanas (UFFS, 2014).
}

Sendo assim, na medida em que a professora propõe um estudo acerca dos processos das sociedades africanas entre os séculos XVI e XIX, para compreender as formas de escravidão que existiram na África visando problematizar as suas características; conhecer e analisar as características do tráfico negreiro e da diáspora; identificar os processos de independência ocorridos em algumas sociedades africanas e compreender a construção do conhecimento acerca da história da África, aspectos estes que vão de encontro no que consta na ementa da 
disciplina: "Estruturas sócio-políticas e culturais da África do século XVI ao XXI, processos de constituição dos sistemas coloniais e de descolonização e abordagens historiográficas e suas perspectivas teóricas e de prática de ensino" (Idem).

Oliva (2009, s/p) aponta sobre aquilo que o texto oficial dos Parâmetros Curriculares Nacionais chama a atenção:

As diferentes formas de escravidão praticadas, inclusive naquele continente, ao indicar a necessidade de "[...] caracterizar e analisar diferentes tipos de escravidão, servidão e trabalho livre", o que permite que estudantes e docentes construam outras imagens dos africanos, contrárias àquelas figuras que os confundem com o exclusivo papel de vítimas da escravidão, alocando-os na função de protagonistas da história e não apenas como coadjuvantes (BRASIL, 1998, p. 55).

Portanto, conforme proposto nos PCNs, na medida em que a professora propõe um estudo sobre diversas formas de escravidão, os/as docentes e estudantes podem passar a ter olhares positivos sobre o continente africano.

Segundo Heck (2013, p. 74), sobre a visão do/a docente ao trabalhar a escravidão, relata em seu trabalho que:

Tal olhar vem sendo objeto de amplo debate na historiografia, principalmente naquelas pesquisas que percebem a condição escrava enquanto situacional, e não como inerente ao sujeito. Neste sentido, se visibiliza as histórias dos homens e mulheres que constituíam amplas identidades e vivências que não podem ser limitadas e/ou esquecidas por suas condições jurídicas.

Além de tudo, a disciplina tem como conteúdo programático envolver no estudo de África, o processo de hominização, para isso, o plano traz aspectos para compreensão deste processo, tais como, as formas de lidar com o passado, dando foco a tradição oral e as demais tradições, bem como seus reinos e estados africanos. Contemplando assim, um dos objetivos gerais da disciplina que se configura em "Estudar os processos históricos do continente africano".

O conteúdo programático parte também de discussões a respeito das relações entre a África e a escravidão, a diáspora africana, o comércio de sujeitos escravizados, a partilha da África, o Pan-africanismo e os caminhos da independência, buscando frisar outro objetivo geral a ênfase nas relações internacionais estabelecidas a partir do século XVI.

E por fim, abarcando um dos objetivos específicos: "Identificar os processos de independência ocorridos em algumas sociedades africanas", tem como conteúdo informações acerca dos processos de independências, como o caso de Angola, Moçambique, Argélia, Quê- 
nia, Marrocos, Tunísia, Líbia, Guiné, Mali, Costa do Marfim, República popular do Congo, África do Sul, Nigéria, Serra Leoa e Egito.

Quadro 1 - Síntese de análise do plano de ensino de "História da África" na UFFS

\begin{tabular}{|c|c|c|c|c|}
\hline Universidade & Disciplina & $\begin{array}{c}\text { Recorte } \\
\text { temporal }\end{array}$ & $\begin{array}{c}\text { Objetivos articulados com a } \\
\text { ementa }\end{array}$ & $\begin{array}{c}\text { Conteúdo programático ar- } \\
\text { ticulado com objetivos }\end{array}$ \\
\hline $\begin{array}{l}\text { Universidade } \\
\text { Federal Fron- } \\
\text { teira Sul } \\
\text { (UFFS) }\end{array}$ & $\begin{array}{l}\text { História da } \\
\text { África }\end{array}$ & XVI e XIX & $\begin{array}{l}\text { Sim, parcialmente, tendo em } \\
\text { vista que ementa visa: estrutu- } \\
\text { ras sócio-políticas e culturais } \\
\text { da África do século XVI ao } \\
\text { XXI. E um dos objetivos ge- } \\
\text { rais: Estudar os processos his- } \\
\text { tóricos do continente africano. } \\
\text { Além disso, a ementa propõe } \\
\text { abordagens historiográficas e } \\
\text { suas perspectivas teóricas e de } \\
\text { prática de ensino. E os objeti- } \\
\text { vos pensam em contemplar } \\
\text { propostas de ensino e de pes- } \\
\text { quisa. }\end{array}$ & $\begin{array}{l}\text { Sim, enfatizando a hominiza- } \\
\text { ção contemplam o objetivo do } \\
\text { estudo acerca dos processos } \\
\text { históricos do continente afri- } \\
\text { cano. E os caminhos sobre as } \\
\text { independências buscam frisar } \\
\text { outro objetivo geral: a ênfase } \\
\text { nas relações internacionais } \\
\text { estabelecidas a partir do sécu- } \\
\text { lo XVI. }\end{array}$ \\
\hline
\end{tabular}

Fonte: Elaborado pelos autores (2015)

Universidade do Estado de Santa Catarina (UDESC)

O curso de História da Universidade do Estado de Santa Catarina (UDESC) privilegia a formação teórica do/a professor/a, composto de disciplinas de conteúdos de História. A matriz curricular contempla a disciplina de História da África I, oferecida para a $2^{\mathrm{a}}$ fase do curso, e de História da África II, oferecida para a $3^{\text {a }}$ fase. A professora responsável pela disciplina é a Dra. Claudia Mortari, esta possui graduação em Licenciatura e Bacharelado em História pela Universidade Federal de Santa Catarina (UFSC/1995), mestrado em História pela Pontifícia Universidade Católica do Rio Grande do Sul (PUC-RS/2000) e doutorado em História pela Pontifícia Universidade Católica do Rio Grande do Sul (PUC-RS/2007). Atualmente é professora de História da África da $\operatorname{UDESC}^{10}$. A análise do plano de ensino que se segue é do primeiro semestre do ano de 2014 e refere-se à História da África I.

10 Estas informações iniciais contidas neste parágrafo foram tecidas a partir da leitura do projeto político pedagógico de curso da UDESC e do currículo lattes da profa. Claudia Mortari. Todos esses documentos estão armazenados pela pesquisa. 
A ementa da disciplina consta que a esta deve percorrer sobre os estudos: "Civilizações africanas entre os séculos XVI e XIX. O impacto da colonização europeia e a escravidão moderna, a presença das culturas islâmicas, e a partilha do continente africano" (UDESC, 2014.1). A Profa. Dra. Cláudia delimita os objetivos gerais da disciplina, o estudante deve:

Analisar algumas características das diversas sociedades africanas, especificamente aquelas pertencentes à chamada África Sul Saariana, entre os séculos XVI e XIX. A ideia é compreender o dinamismo dessas sociedades nas suas formas de organização, no que há de comum e de específico entre elas, nas suas determinações e dinâmicas internas e nas relações estabelecidas entre os povos africanos e àqueles fora do continente (Idem).

Partindo novamente dos pressupostos sobre os PCNs discutidos por Oliva (2009), num determinado momento estes parâmetros dão um salto das primeiras civilizações para o processo de Expansão Marítima Europeia dos séculos XV e XVI, trazendo assim a África como tema secundário. Sendo assim, mais uma das cautelas na delimitação do recorte cronológico.

Vale destacar, assim como a UFFS, o plano de ensino da UDESC, busca o dinamismo, destacando as relações internas e externas do continente. Em relação aos objetivos específicos da disciplina, dentre os oito pontos apresentados, focamos naqueles que estão relacionados à ementa da disciplina:

- Estudar os processos de organização das sociedades africanas, especificamente aquelas pertencentes à região sul saariana, entre os séculos XVI e XIX, suas diversidades e complexidades objetivando construir uma visão crítica acerca dos seus processos transformação provenientes de ações endógenas e exógenas ao continente.

- Problematizar o processo de construção de novas configurações de identidades no interior do continente a partir da influência do tráfico atlântico e, também, no Novo Mundo, com a diáspora imposta pelo tráfico de africanos escravizados.

- Estudar o contexto da segunda metade do século XIX nas Áfricas a partir do processo de disputas europeias visando compreender as causas internas e externas da ocupação colonial e o processo de Partilha do continente com ênfase na perspectiva africana (UDESC, 2014).

O conteúdo programático é dividido em quatro momentos e contemplam inicialmente, os estudos africanos pautados no motivo de porque estudar a História da África e as Relações entre Brasil e África e as Leis Educacionais, neste momento é ressaltado o estudo sobre Historiografia africana e africanista, novas formas de pensar a África e maneiras de como lidar com o passado (UDESC, 2014).

Neste primeiro momento do conteúdo programático, a disciplina articula-se ao que demandam as DCN's para ERER quando “em História da África, tratada em perspectiva positiva, não só de denúncia da miséria e discriminações que atingem o continente, nos tópicos per- 
tinentes se fará articuladamente com a história dos afrodescendentes no Brasil” (BRASIL, 2004, p. 21).

No segundo momento, a disciplina busca a compreensão das sociedades africanas entre os séculos XVI e XIX pensando nas formas de organização socioeconômica e política e aspectos da sua cultura, através de um entendimento acerca dos Estados Sudaneses ao redor do Saara, a Costa do Ouro, o Atlântico, o Benin e o Delta do Níger, a África Centro-Ocidental: o Congo e Angola, e por fim a Costa Oriental: a Zambézia. Neste momento é importante ressaltar aquilo que Oliva (2009) aborda sobre os PCNs, mesmo que implícito neste documento, a perspectiva é que a África deve ser estudada a partir de suas sociedades tradicionais e não por suas formações estatais e civilizações.

Ademais neste período da disciplina é possível perceber que um dos objetivos gerais são contemplados: "Analisar algumas características das diversas sociedades africanas, especificamente aquelas pertencentes à chamada África Sul Saariana, entre os séculos XVI e XIX” (UDESC, 2014). Além disso, a disciplina propõe estudos amplos sobre os países do continente africano, bem como suas especificidades.

No terceiro momento, a disciplina contempla o impacto da colonização europeia e a escravidão moderna, visando à escravidão nas Áfricas e o tráfico atlântico destacando a África das feitorias e encraves costeiros. E o quarto e último momento o caminho percorrido representa a partilha do continente africano no final do século XIX: dominação e resistência.

Quadro 2 - Síntese de análise do plano de ensino de "História da África I" na UDESC

\begin{tabular}{|c|c|c|c|c|}
\hline Universidade & Disciplina & $\begin{array}{l}\text { Recorte } \\
\text { temporal }\end{array}$ & $\begin{array}{c}\text { Objetivos articulados com } \\
\text { a ementa }\end{array}$ & $\begin{array}{l}\text { Conteúdo programático ar- } \\
\text { ticulado com objetivos }\end{array}$ \\
\hline $\begin{array}{l}\text { Universidade do } \\
\text { Estado de Santa } \\
\text { Catarina (U- } \\
\text { DESC) }\end{array}$ & $\begin{array}{l}\text { História da } \\
\text { África I }\end{array}$ & $\begin{array}{l}\text { XVI e } \\
\text { XIX }\end{array}$ & $\begin{array}{l}\text { Sim, a ementa visa contem- } \\
\text { plar as civilizações africanas } \\
\text { entre os séculos XVI e XIX. } \\
\text { E os objetivos: analisar al- } \\
\text { gumas características das } \\
\text { diversas sociedades africa- } \\
\text { nas, especificamente aquelas } \\
\text { pertencentes à chamada Á- } \\
\text { frica Sul Saariana, entre os } \\
\text { séculos XVI e XIX. }\end{array}$ & $\begin{array}{l}\text { Sim, um dos objetivos é anali- } \\
\text { sar algumas características das } \\
\text { diversas sociedades africanas, } \\
\text { especificamente aquelas per- } \\
\text { tencentes à chamada África } \\
\text { Sul Saariana, entre os séculos } \\
\text { XVI e XIX. E o conteúdo pro- } \\
\text { gramático: compreensão das } \\
\text { sociedades africanas entre os } \\
\text { séculos XVI e XIX: formas de } \\
\text { organização socioeconômica e } \\
\text { política e aspectos da sua cul- } \\
\text { tura. }\end{array}$ \\
\hline
\end{tabular}

Fonte: Elaborado pelos autores (2015) 


\section{UNIVERSIDADE COMUNITÁRIA}

\section{Universidade do Extremo Sul Catarinense (UNESC)}

O curso de História da Universidade do Extremo Sul Catarinense (UNESC) evidencia uma visão de história preocupada com questões sociais e ambientais. Além de tudo o curso tem como missão formar um profissional de história com habilidades e competências para atuar tanto no ensino como na pesquisa, tendo sempre em vista a melhoria da qualidade do ambiente de vida na Região Sul de Santa Catarina.

Na matriz curricular, a disciplina História da África está inclusa, e é lecionada pela Professora Ma. Lucy Cristina Ostetto, esta possui graduação em História pela Universidade Federal de Santa Catarina (UFSC/1992) e mestrado em História pela mesma Universidade (1997). Atualmente é Professora dos cursos de História e Pedagogia na Universidade do Extremo Sul Catarinense (UNESC). O plano de ensino analisado da disciplina História da África é do segundo semestre de 2014.

$\mathrm{Na}$ ementa da disciplina consta: "abordar temas como as civilizações africanas entre os séculos XVI e XIX, o impacto da colonização europeia e a escravidão, a presença das culturas islâmicas e por fim a partilha do continente africano, as culturas africanas da atualidade" (UNESC, 2014). Os objetivos da disciplina proposto pela Professora Ma. Lucy busca:

\footnotetext{
Problematizar a Lei 10.639/03 e suas diretrizes, como subsídios para diferentes abordagens da História e Cultura Afro-brasileira e Africana no cotidiano escolar; Refletir sobre a (in) visibilidade dos povos Africanos e Afro-brasileiros nos livros de história; Buscar uma aproximação com a História da África, dando visibilidade as principais dinâmicas históricas das sociedades africanas, vislumbrando uma discussão sobre suas estruturas políticas, econômicas, sociais e culturais, e as relações estabelecidas com universos e povos distintos em três momentos diferentes. O primeiro se refere ao período que antecede à expansão marítima europeia, o segundo a chegada dos europeus ao continente e sua posterior colonização e o terceiro ao contexto pós-colonial. E por fim compreender a importância da História e da Cultura Africana e Afro-brasileira na formação da sociedade brasileira (Idem).
}

Além disso, o conteúdo programático, assim como na UDESC, está dividido em quatro momentos articulados com alguns objetivos da ementa. No primeiro momento, a professora visa focar num olhar direcionado à África. A Lei 10.639/03 é contemplada com destaque, conforme previsto nos objetivos: "Problematizar a Lei 10.639/03 e suas diretrizes, como subsídios para diferentes abordagens da História e Cultura Afro-brasileira e Africana no cotidiano escolar; Refletir sobre a (in) visibilidade dos povos Africanos e Afro-brasileiros nos livros de história" (Idem). 
Contribuindo para esta linha de pensamento, anteriormente apontamos aspectos para pensar o continente africano por ele mesmo, assim, era necessário buscar sua relação com os eventos históricos externos e internos. Entretanto é preciso ter cuidado para que não ocorra equívocos procedendo a uma abordagem sobre a África num segundo plano.

Num segundo momento dos conteúdos programáticos do plano de ensino, é enfatizando aspectos geográficos, os estados sudaneses em África negra, os estados e as culturas da Guiné inferior, do Delta do Níger aos Camarões: os fon e os iorubá, os estados haussas, o reino do Congo e seus vizinhos e a região ao sul do Zambeze. Contemplando os objetivos:

Buscar uma aproximação com a História da África, dando visibilidade as principais dinâmicas históricas das sociedades africanas, vislumbrando uma discussão sobre suas estruturas políticas, econômicas, sociais e culturais, e as relações estabelecidas com universos e povos distintos em três momentos diferentes (UNESC, 2014).

No terceiro momento busca outros olhares para África e a escravidão, e a escravidão transatlântica. E por fim, no quarto momento são destacados os olhares contemporâneos, a conferência de Berlim, o discurso racial e a partilha da África, a África depois da partilha e África e Brasil: diálogos historiográficos.

Vale destacar que neste plano de ensino os conteúdos, objetivos e ementa estão articulados de alguma forma, pois na medida em que se tem uma abordagem sobre a invisibilidade da população africana e afro-brasileira, se faz necessário discutir as implicações das Leis Federais $10.639 / 03$ e $11.645 / 08^{11}$.

Ademais o contexto histórico não relatado na historiografia a partir dos seus próprios pressupostos, o resultado para isto são os impactos na sociedade contemporânea, por isso a necessidade de contemplar o objetivo da disciplina: "compreender a importância da História e da Cultura Africana e Afro-brasileira na formação da sociedade brasileira" (UNESC, 2014).

11 A lei 11.645/08 altera a Lei 9.394/96 modificada pela Lei 10.639 tornando obrigatório o estudo da história e cultura afro-brasileira e indígena nos estabelecimentos de ensino fundamental e de ensino médio, públicos e privados. 
Quadro 3 - Síntese de análise do plano de ensino de "História da África I" na UNESC

\begin{tabular}{|c|c|c|c|c|}
\hline Universidade & Disciplina & $\begin{array}{l}\text { Recorte } \\
\text { temporal }\end{array}$ & $\begin{array}{l}\text { Objetivos articulados } \\
\text { com a ementa }\end{array}$ & $\begin{array}{c}\text { Conteúdo programático ar- } \\
\text { ticulado com objetivos }\end{array}$ \\
\hline $\begin{array}{l}\text { Universidade } \\
\text { do Extremo Sul } \\
\text { Catarinense } \\
\text { (UNESC) }\end{array}$ & $\begin{array}{l}\text { História da } \\
\text { África }\end{array}$ & XVI e XIX & $\begin{array}{l}\text { Sim, a ementa busca: a- } \\
\text { bordar temas como as civi- } \\
\text { lizações africanas entre os } \\
\text { séculos XVI e XIX. E os } \\
\text { objetivos: visibilidade as } \\
\text { principais dinâmicas histó- } \\
\text { ricas das sociedades afri- } \\
\text { canas, vislumbrando uma } \\
\text { discussão sobre suas estru- } \\
\text { turas políticas, econômi- } \\
\text { cas, sociais e culturais, e as } \\
\text { relações estabelecidas com } \\
\text { universos e povos distintos } \\
\text { em três momentos diferen- } \\
\text { tes. }\end{array}$ & $\begin{array}{l}\text { Sim, possui conteúdo progra- } \\
\text { mático a Lei 10.639/03 e o } \\
\text { ensino de História, o ensino da } \\
\text { História e Cultura africana e } \\
\text { afro-brasileira em Sala de Au- } \\
\text { la, neste momento é comtem- } \\
\text { plada, destacando aquilo pre- } \\
\text { visto nos objetivos: } \\
\text { Problematizar a Lei 10.639/03 } \\
\text { e suas diretrizes, como subsí- } \\
\text { dios para diferentes aborda- } \\
\text { gens da História e Cultura } \\
\text { Afro-brasileira e Africana no } \\
\text { cotidiano escolar. }\end{array}$ \\
\hline
\end{tabular}

Fonte: Elaborado pelos autores (2015)

\section{Considerações finais: alguns apontamentos}

Em cada plano de ensino das instituições, os objetivos, conteúdos programáticos e as ementas estão articulados basicamente entre relatar o processo histórico do continente africano a partir de suas especificidades, abordar a Lei Federal 10.639/03 pensando na contemporaneidade e os métodos educacionais de abordagem da temática. Além disso, consta nos planos de ensino uma parcial articulação entre os objetivos, conteúdos programáticos e ementas nas três universidades.

A partir das analises feitas é possível apontar um aspeto sobre todas as instituições pesquisadas, UFFS (pública), UDESC (pública) e UNESC (comunitária): a escolha do recorte temporal entre os séculos XVI e XIX para o estudo da história do continente Africano, momento do processo de colonização de África a partir da penetração dos europeus.

Para Amilton Azevedo (2013) as representações construídas sobre o continente e suas populações entre os séculos XVI e XX e nos condicionaram a pensar as relações da África com o Mundo Atlântico a partir de perspectivas que a sugerem como um acidente geográfico, entre Oriente e o Ocidente, transformando até mesmo em paradigma que se expandiu nos modos de interpretar o continente no campo historiográfico. Ainda segundo ele, somos educados a compreender as relações atlânticas como um projeto balizado na expansão do Estado Nação, 
da economia capitalista e dos desdobramentos da modernidade europeia. "Desse modo, as Áfricas e as Diásporas sofrem um esvaziamento de memórias quando associadas apenas a historicidade europeia" (AZEVEDO, 2013, s/p).

Pode-se apontar portanto a influência do modelo quadripartite para a configuração do ensino de história, que divide temporalmente história da humanidade pautada na história europeia: História Antiga, História Medieval, História Moderna e História Contemporânea. Todavia, não pensamos o recorte temporal dos planos de ensino em relação ao modelo quadripartite, mas a história europeia enquanto como marco referencial para o estudo dos eventos históricos do continente Africano.

Ademais é importante pensar, que as instituições se atentam a implementação da 10.639/03 citada em seus planos, isso indica talvez, a não necessidade de nova legislação, mas de aprimoramento da fiscalização por parte dos órgãos federais, inclusive com a produção de indicadores que nos permitam acompanhar a implementação de fato e a qualidade dos conteúdos ministrados.

\section{Referências}

AZEVEDO, Amailton Magno. Imagens da África: Entre a violência discursiva e a produção de memória. A cor da Cultura, 2013. Disponível em:

http://www.acordacultura.org.br/artigos/23092013/imagens-da-africa-entre-a-violenciadiscursiva-e-aproducao-de-memoria Acesso em: nov. 2015.

BRASIL, Ministério da Educação. Diretrizes Curriculares Nacionais para a Educação das Relações Étnico-Raciais e para o Ensino de História e Cultura Afro-Brasileira e Africana, 2004.

CARDOSO, Paulino de Jesus Francisco. A Lei 10.639/03: significados e desafios na luta antiracista no Brasil, 2007. Disponível em:

http://multiculturalismoepopulacoesafricanas.blogspot.com.br/2007/11/desafios-daimplantaao-da-lei-10639-03.html Acesso em: ago. 2015.

HECK, Mariana. Identidades e Multiculturalismo: um estudo acerca do Ensino de História das Áfricas nas Universidades Públicas de Santa Catarina (2011-2012). Trabalho de Conclusão de Curso (Graduação em Bacharelado e Licenciatura em História) - Universidade do Estado de Santa Catarina, Florianópolis, 2013.

LIMA, Mônica. A África na Sala de Aula. Nossa História, ano 1, n. 4, fev./2004.

MATTOS, Wilson Roberto de. PENA, Patrícia Carla Alves. Em torno do Ensino de História da África na Bahia: breves considerações gerais. Revista de História Comparada, Rio de Janeiro, v. 7, n. 2, p. 216-243, 2013. 
OLIVA, Anderson Ribeiro. A história africana nas escolas brasileiras. Entre o prescrito e o vivido, da legislação educacional aos olhares dos especialistas (1995-2006). História, São Paulo, v. 28, n. 2, 2009.

PACHECO, Ana Júlia. História da África no curso de graduação em História de Instituições Comunitárias de Ensino Superior de Santa Catarina: Perspectivas, avanços e desafios. 2014. Trabalho de Conclusão de Curso (Graduação em Bacharelado e Licenciatura em História) Universidade do Estado de Santa Catarina, Florianópolis, 2014.

PANTOJA, Selma. A África imaginada e a África real. In: PANTOJA, Selma; ROCHA, Maria José. (Org.). Rompendo Silêncios: História da África nos currículos da educação básica. Brasília: DP Comunicações, 2004.

PEREIRA, Amilcar Araujo. Escola mais justa: o ensino de História e cultura afro-brasileira e africana dá os primeiros passos. Revista de História.com.br, 2011. Disponível em:

http://www.revistadehistoria.com.br/secao/educacao/escola-mais-justa Acesso em: nov. 2015.

ROMÃO, Jeruse. O Movimento Negro Brasileiro e as Diretrizes da Educação Nacional: A Lei Federal 10.639/2003. In: CARDOSO, Paulino de Jesus Francisco. RASCKE, Karla Leandro. Formação de professores: produção e difusão de conteúdos sobre história e cultura afrobrasileira e africana. Florianópolis: DIOESC, 2014.

\section{Fontes}

UDESC, Universidade do Estado de Santa Catarina. Plano de ensino da disciplina História da África I, 2014.

UFFS, Universidade Federal Fronteira Sul. Plano de ensino da disciplina História da África, 2014.

UNESC, Universidade do Extremo Sul Catarinense. Plano de ensino da disciplina História da África, 2014.

Recebido em 11 de agosto de 2015.

Aceito em 10 de setembro de 2015. 
